\title{
The Imagined And The Concrete: What is an Artifact?
}

\author{
by Susan M. Hagan, Carnegie Mellon University
}

Keywords: Design, communication, culture, argument, rhetoric

A few years ago, in conversation with a friend in engineering, I mentioned that I had been collecting and analyzing artifacts - conference covers, magazine layouts, art history texts - anything that might help me understand how words, typography, and images collaborate on the page to make messages that could not be produced by text or image alone. But our discussion did not get past my use of the term artifact. My colleague simply could not wrap his mind around the idea that an artifact's third dimension could be so narrow, its material so contemporary, and its value so seemingly insignificant. He cautioned me against the use of that term. I conceded the point. Were I to encounter that friend today, I would not only apply the term artifact to my data, I would take that claim further. An artifact is more than the object that stubs our toes or the ancient document that tears at the edges; it goes beyond the virtual bits we see but cannot touch. An artifact is, in part, a product of the collective memory (Middleton \& Edwards, 1990), or as Alan Radley (1990) conveys, an object that has been transformed for special purposes within the culture. However, I would argue that an artifact is first and foremost the fragile residue of memory crafted into a mental representation by an individual. Artifacts of the mind live only as long as individuals can hold them, and like the objects found on a dig, can be left untouched, until one day they become a persuasive act, one which might or might not reach further than that single mind. To those of you already complaining that I am about to make a word mean nothing by making it mean everything, stay with me a bit longer.

That an artifact is something made by a human being, a thing with archaeological or cultural interest, is not in question. But how does it come to be that thing? For example, how might I transform a 1985 blue Pontiac Bonneville from an old wrecked car into an artifact of intrest? Part of that persuasive effect depends on the reach of this particular journal (Kaufer \& Carley, 1993), but part will lie with my ability to convince you to remake steel and glass, paint and canvas, and these bits you see on your computer screen into a mental artifact of my design. The Pontiac Bonneville in question was just a car until the night another car crossed over the centerline of a four-lane highway and crashed headon into it. In that moment the Bonneville, my father's car, took on special purposes. What was once an object, which my father loved for its comfortable relationship with his bad back, had now become a vehicle of thought, a vehicle through which I would try to understand what had happened. I drove it daily.

One day, not too long after the accident, I drove my fragile residue of memory to the Andy Warhol Museum thinking that the soup cans and silver balloons might distract me. I had never had much patience with or interest in Warhol's work. I'd always thought of it as a somewhat self-indulgent, one-note oeuvre. But because I live in Pittsburgh Pennsylvania, the home of the Andy Warhol Museum, I find myself there from time to time. The distraction worked until my blue Bonneville appeared again in the form of a 32-canvas series that also includes an automobile, which I used as my implicit focal point. The series is called Jackie. It documents the moments before and after the death of President John Kennedy on 22 November 1963 as he rode in the back seat of a 1961 blue Lincoln Continental. This series does not match the timeline of events that took place on that day, but it did match my mental state. For that reason, I transformed it from an object with historical importance to an object used for my special purposes. While you, 
my reader, might never see or touch the Bonneville or the painting, touching and seeing those objects might undermine the construction of the mental artifact I want you to possess. Seeing an actual Bonneville would not produce what I hope you will construct. While seeing is often critical to understanding, as it was when my blue Pontiac merged with Warhol's painting, now I must reform both as a persuasive act. They must live as the residue of sight, constructed from a few verbal clues that focus on my interests.

Notice as you read these words that nowhere do you see a reproduction of Warhol's Jackie. Similarly, nowhere do you see a picture of the blue Bonneville. My decision might seem odd because visual/verbal communication often has compelling persuasive value. But again, I do not want your artifact of mind to focus on the specifics of Jackie's face or hair, or on the 1961 Lincoln, or on the less grand Bonneville. I will only succeed in my persuasive act of artifact construction if the Lincoln and the Bonneville are transformed into a tool for the special purpose of understanding the time chaos felt by those who have experienced sudden loss. In fact, my Bonneville blended with Warhol's series of canvases, because that mental collaboration so achingly mirrored the time chaos I felt for days after the accident.

Warhol used 32 square canvases to place and repeat a small group of photographs of the president's wife taken just before and just after the shooting. These images are not placed and repeated in the order in which they occurred, moving from happiness to sorrow, but instead they are put into a kind of flashback filmstrip that allows the viewer to see images that first show sorrow, later joy, then sorrow, only to see the beaming smile again in the next canvas. It is the remembrance of the joy that was there just a split second ago, only to be replaced by the sorrow, which made it difficult for me to look at that series directly. They had just been there, in that blue Bonneville, healthy, whole. Then they were not. It was an instant that could have been prevented had my mother dropped her wallet and stopped to retrieve it - I saw all of that when I merged my fragile memory with a blue 1961 Lincoln Continental and the woman who survive. More than any other object I have encountered, those 32 canvases have allowed my artifact of mind, my wrecked blue Bonneville in the form of a 1961 Lincoln, to become my true vehicle for understanding.

While Warhol might have wished to build a different artifact, one that echoed an obsession with sensationalism and celebrity, that is the thing about artifacts and individuals. I'm drawn to what he made, not as the thing he might wish me to see, but as the thing I construct; an artifact that echoes the culture of tragedy rather than the culture of celebrity. As a persuasive tool, I hope the words I have used to construct this artifact will direct your eye to my areas of interest (Yarbus, 1967) while making it harder for you to imagine this image in your own way for your own purposes.

Warhol's series has no words except for the title Jackie, which allows many shades of meaning to emerge (Solso, 1994) even as it makes its spatial relationships heartbreakingly explicit. My artifact, on the other hand, is made of typography and words that ask that you build a world from a few verbal cues. I do this in the hope of diminishing the concrete in favor of the imagined - allowing you in this small case, for my small purposes, to choose the inspiration rather than the encounter.

I frankly don't care about Warhol's intentions. Whether or not he meant to show the gravity of a public death, echo a woman's suffering, or just play celebrity watcher is beyond my concerns. The artifact I've constructed leaves me in awe that such a small amount of visual information could produce the feeling that someone is gone, while still conveying the sense that it should be easy to move just an instant into the past in order to recapture the Bonneville that was lost to the future. While we cannot rearrange life as he rearranged his canvases, my imagined sequence has always left me feeling the need for a time machine, another artifact of the mind, which could move away from the accident and hold forever to earlier images, the ones where nothing bad had happened yet. These new juxtapositions make a visceral comment on the time chaos of tragedy, one that might never reach a larger culture. Even so, your experience within this mental artifact might change your focus on Jackie from the residue of a national tragedy to the residue of a personal tragedy - a vehicle for time chaos. 
For that reason, my words do not feature aspects of the artifact you might find most obvious in the presence of the painting: the deep blue, turquoise blue, and gold on which all of the images of Jackie, whose own image is in black, are screened. Color is not a part of my mental artifact. But the fact that his screenprinting technique is machine-like might have diminished painterly undercurrents, and in that way made a better machine for time chaos. There is no painterly undertone that would interfere with my involvement with the construction of my artifact. Technique doesn't take my attention from joy or sorrow. While much of Warhol's work seems to put style first, this woman seems utterly real, which helped me to construct myself as a real person beside her in my own vehicle.

In wanting you to see this reality, I have tried to construct an artifact in your mind; one that has aspects of steel and glass, canvas, and paint, word and image, culture and individual. That artifact exists in the slippery contexts that inform the way we think of things, allowing multiple objects to morph from ordinary purposes to my purposes. Those purposes began long ago because I missed my mother. I consumed and reconstructed anything I saw, and in doing so, eventually made some sense of time chaos by building a persuasive act that would help me share that turmoil. After all, isn't that really what an artifact is a way to share the act of making sense.

\section{ABOUT THE AUTHOR}

Susan Hagan received her Masters of Design and her Ph.D. in Rhetoric from Carnegie Mellon University where she studied the meaning effects and persuasive possibilites in visual/verbal design. She continues this work as a postdoctoral fellow at Carnegie Mellon. She is also a member of the Advisory Board of Artifact, and a consultant who writes, presents, and teaches on the topic of visual/verbal and multi-modal collaboration, and is now editing her dissertation for journal and book publication.

\section{REFERENCES}

Kaufer, D. S., \& Carley, K. M. (1993). Communication at a distance: The influence of print on sociocultural organization and change. Hillsdale, NJ: Lawrence Erlbaum.

Middleton, D., \& Edwards, D. (1990). Collective remembering. London: Sage Publications.

Radley, A. (1990). Artefacts, memory and a sense of the past. In D. Middleton \& D. Edwards (Eds.), Collective remembering: Inquiries in social construction (pp. 4659). Newbury Park, CA: Sage Publications.

Solso, R. L. (1994). Cognition and the visual arts. Cambridge, MA: MIT Press.

Yarbus, A. L. (1967). Eye movements and vision (B. Haigh, Trans.). New York: Plenum Press.

\section{CORRESPONDENCE}

Susan Hagan, Ph.D. MDes, Carnegie Mellon University, 245Baker Hall, 5000 Forbes Avenue, Pittsburgh, PA 15213-3890, USA.

E-mail:susan.hagan@alumni.cmu.edu

Published online 2006-08-18

ISSN 1749-3463 print/ ISSN 1749-3471

DOI: 10.1080/17493460600610855

(C) 2007 Artifact 